\title{
Dictamnus albus (Diptam), eine äußerst attraktive Staude in der Steppenwiese des Palmengartens
}

Hilke Steinecke

Diptam ist in Mittel- und Südeuropa heimisch. Bei uns kommt die Staude nur an warmen, trockenen Standorten vor und ist in Hessen eine bedrohte Art. Als Zierpflanze werden im Garten auch weißblütige Formen kultiviert. Die dunklen Linien auf den Blütenblättern weisen den Bestäubern den Weg zum Blüteninnern und zum Nektar. Wie auch Weinraute und Citrus (alles Rutaceae) enthält Diptam reichlich ätherische Öle. Die ganze Pflanze, auch Teile der Blüte und später die Früchte, sind von Drüsen überzogen. Die reifenden Früchte geben so viel ätherisches Öl ab, dass Tröpfchen entstehen, die an sonnigen Tagen eine Brennglaswirkung haben. Dadurch kann es zur Selbstentzündung kommen. Diptam wurde deshalb gelegentlich für den brennenden Busch aus der Bibel gehalten, auch wenn er keine Dornen hat und nicht im Heiligen Land vorkommt.
Vorsicht ist geboten, wenn man der Pflanze zu nahe kommt. Die ätherischen Öle enthalten phototoxische Furanocumarine, die auch in der Herkulesstaude vorkommen. Bei Berührung und Sonneneinfluss können auf der Haut schwere verbrennungsartige Symptome und Blasenbildung auftreten.

Im sonnig-trockenen Frühjahr und Frühsommer 2018 blühte Diptam in der Steppenwiese besonders üppig. Schöne Farbkontraste entstanden, als zeitgleich der Türken-Mohn in unmittelbarer Nähe seine großen orangeroten Blüten öffnete.

\section{Anschrift der Autorin}

Dr. Hilke Steinecke, Palmengarten Frankfurt, Siesmayerstraße 61, 60323 Frankfurt, E-Mail: hilke.steinecke@ stadt-frankfurt.de

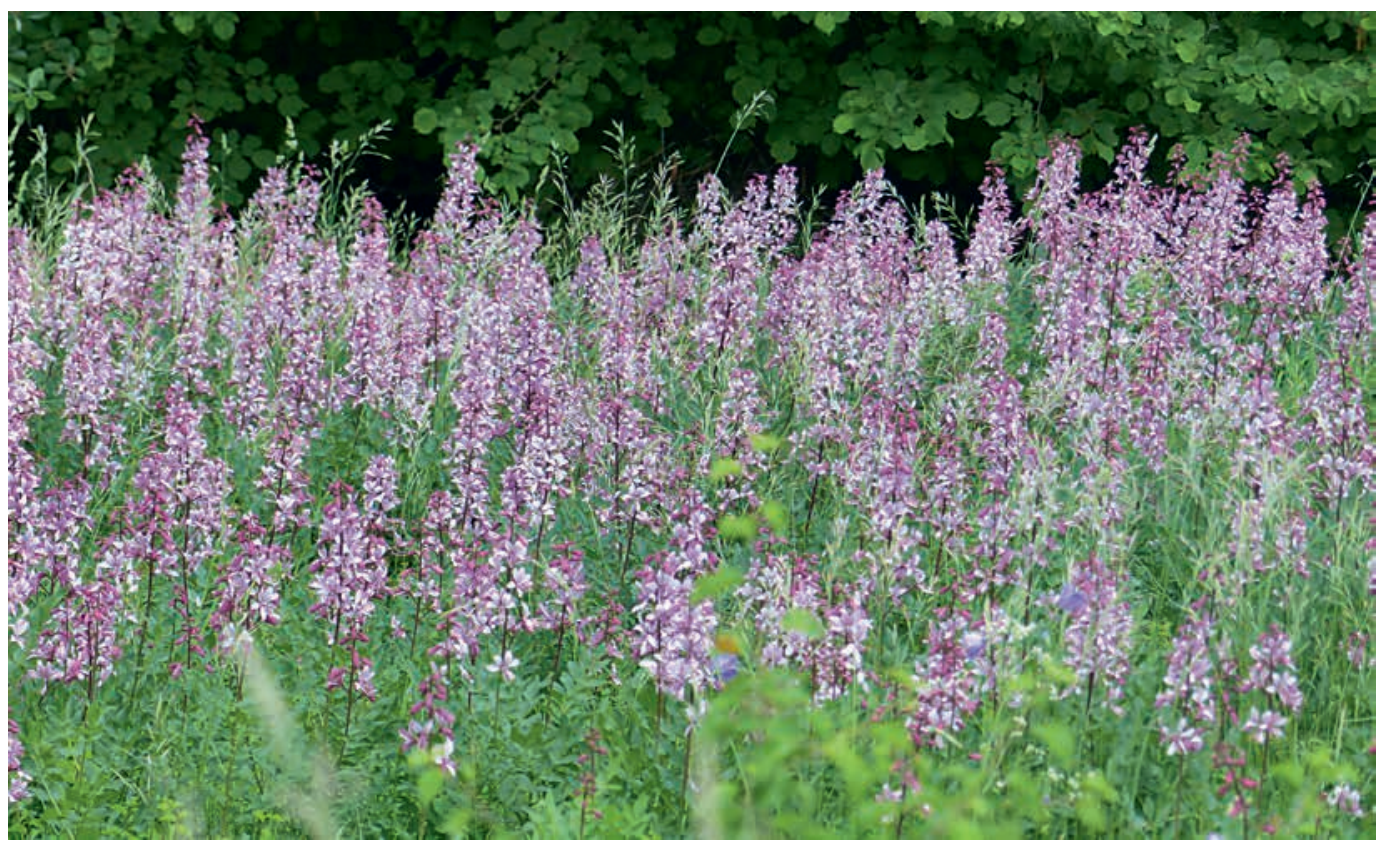

Abb. 1: Ein üppiger Wildbestand von Diptam am Sponsheimer Berg bei Laubenheim/Nahe (Rheinland-Pfalz). (Foto: H. STEINECKE) 


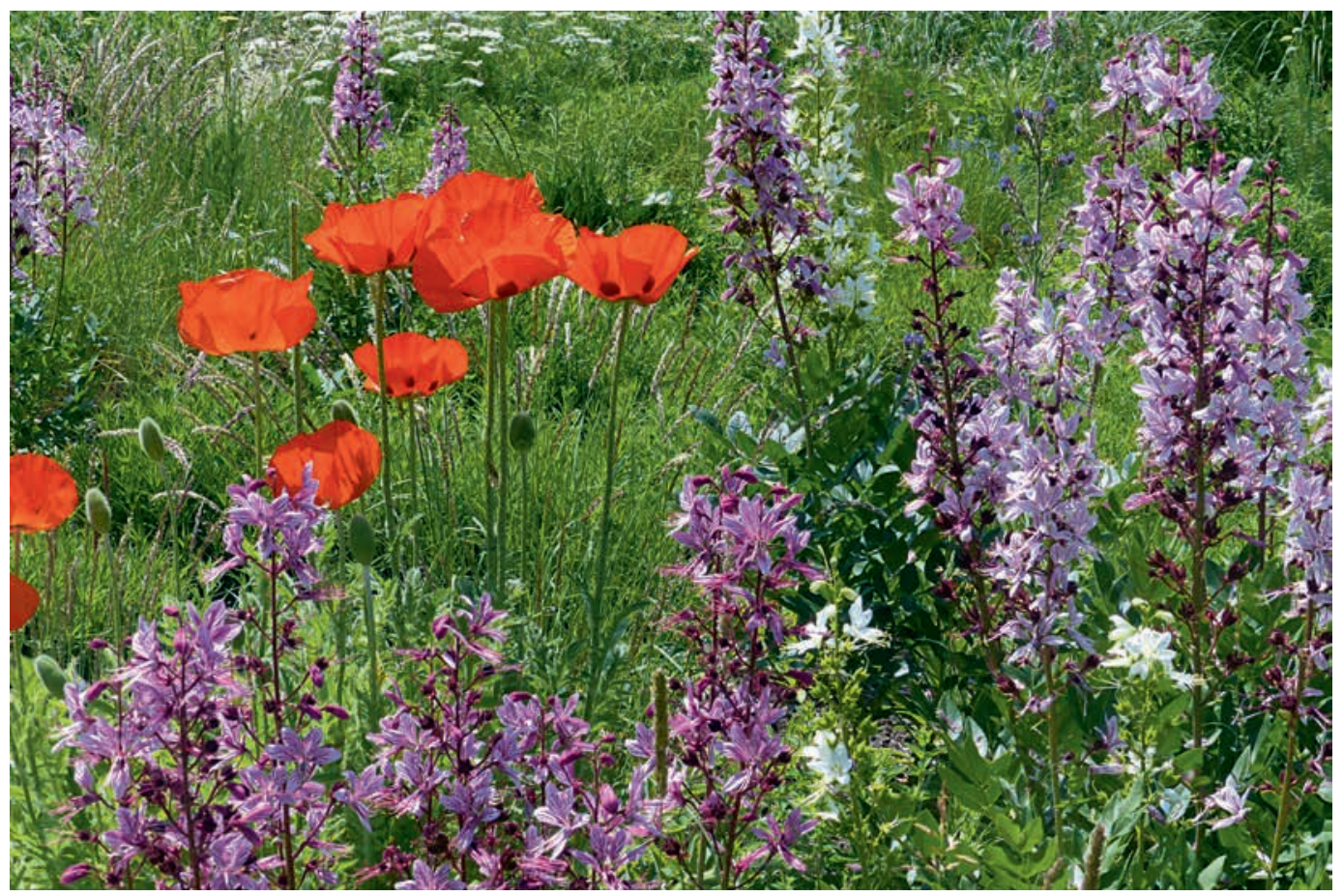

Abb. 2: Weiß- und rosablütiger Diptam zusammen mit Türkenmohn in der Steppenwiese. (Foto: H. Steinecke)

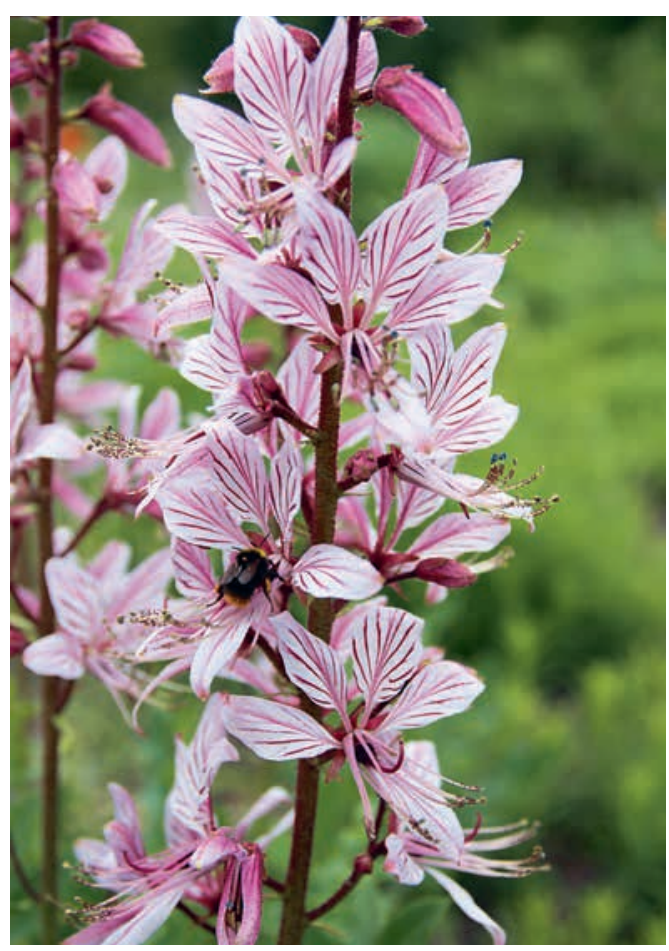

Abb. 3: Blütenstand von Dictamnus albus mit Hummelbesuch. (Foto: H. STEINECKe)

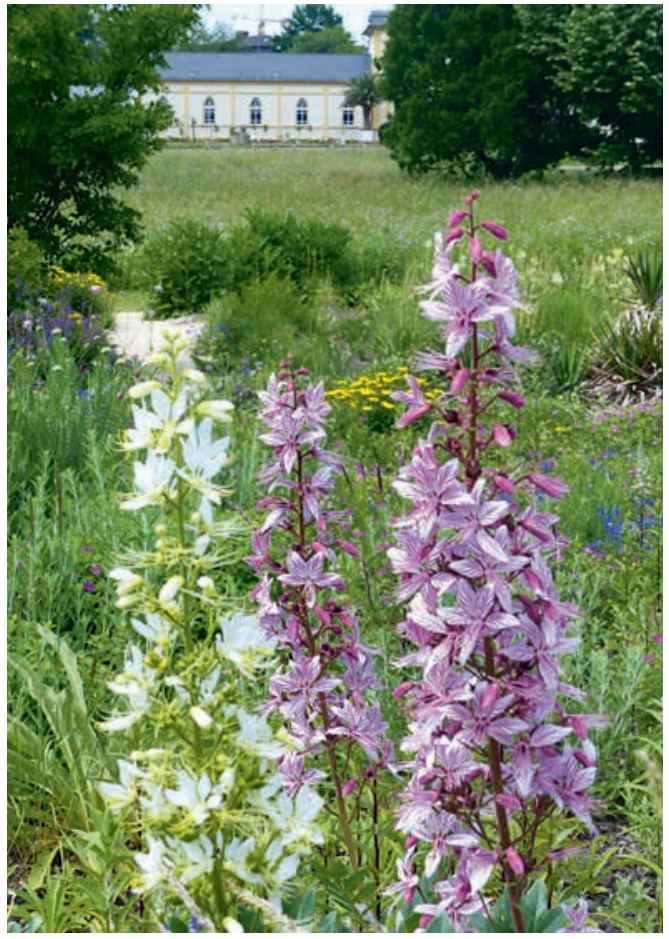

Abb. 4: Weißer und rosa Diptam in der Steppenwiese im Palmengarten. (Foto. H. STEINecke) 